\title{
Medical faculty members' perspectives on the components of cross-cultural competence in the Islamic Republic of Iran: a qualitative study
}

M. Mousavi Bazaz, ${ }^{1}$ A. Zabihi Zazoly ${ }^{2}$ and H. Karimi Moonaghi ${ }^{2}$

$$
\begin{aligned}
& \text { وجهات نظر أعضاء هيئة التدريس الطبي حول مكونات الكفاءة العابرة للثقافات في جمهورية إيران الإسلامية: دراسة كيفية }
\end{aligned}
$$

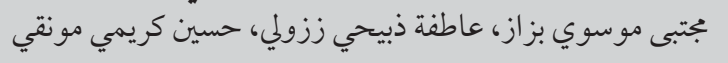

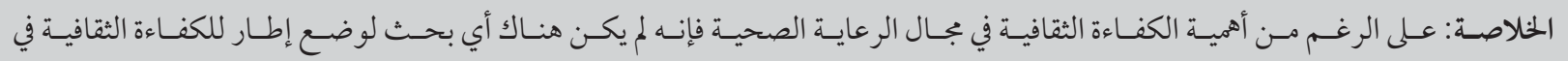

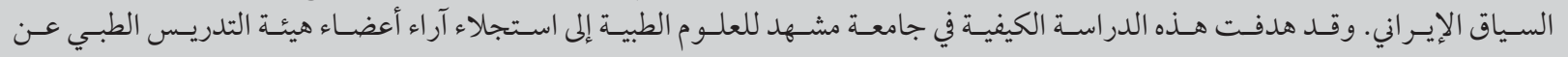

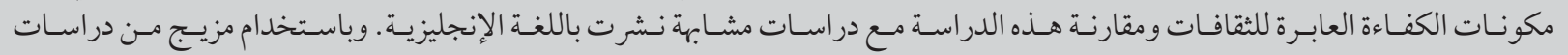

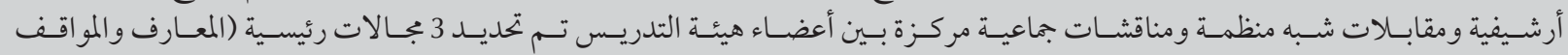

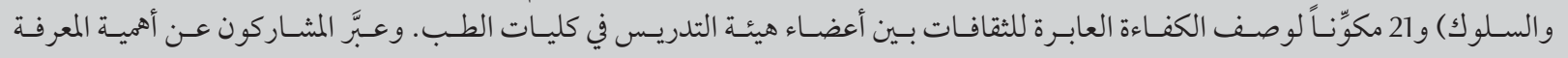

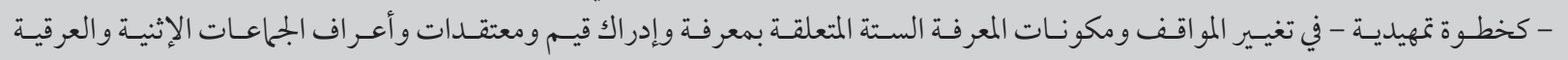

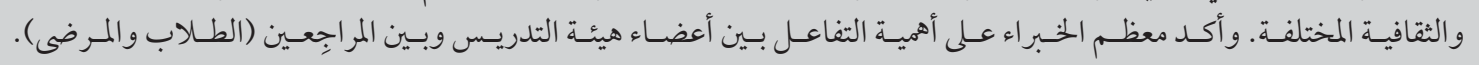

ABSTRACT Despite the importance of cultural competence in health care, there has been no research to develop a framework for cultural competence in the Iranian context. This qualitative study at Mashhad University of Medical Sciences aimed to elucidate the views of medical faculty staff on the components of cross-cultural competence and compare these with similar studies published in English. Using a combination of archival studies, semi-structured interviews and focus group discussions among faculty members 3 major domains (knowledge, attitude and behaviour) and 21 components were identified to describe the cross-cultural competence of faculty members in medical schools. Participants expressed the importance of knowledge as a precursor to changing attitudes and the 6 knowledge components related to knowledge and awareness of values, beliefs and norms of different ethnic, racial and cultural groups. Experts mostly emphasized the importance of interaction between faculty members and clients (students and patients).

Points de vue des membres de la faculté de médecine sur les composantes de la compétence interculturelle en République islamique d'Iran : étude qualitative

RÉSUMÉ Malgré l'importance de la compétence culturelle en soins de santé, il n'existe pas de recherche visant à établir un cadre pour la compétence culturelle dans le contexte iranien. La présente étude qualitative à I'Université des sciences médicales de Mashhad visait à élucider les points de vue du personnel de la faculté de médecine sur les composantes de la compétence interculturelle et à les comparer à des études similaires publiées en langue anglaise. À l'aide d'une association d'études d'archives, d'entretiens semistructurés et de groupes de discussions thématiques impliquant les membres de la faculté, trois domaines principaux (les connaissances, les attitudes et les comportements) ont été dégagés et 21 composantes ont été identifiées pour décrire la compétence interculturelle à acquérir par les membres des facultés de médecine. Les participants ont insisté sur l'importance des connaissances comme élément précurseur permettant une évolution des attitudes et sur les six composantes dans ce domaine liées à la connaissance des valeurs, des croyances et des normes dans différents groupes ethniques, raciaux et culturels et à la sensibilisation en la matière. Les experts ont surtout souligné l'importance de l'interaction entre les membres de la faculté et les clients (les étudiants et les patients).

${ }^{7}$ Department of Community Medicine; ${ }^{2}$ Department of Medical Education, Faculty of Medicine, Mashhad University of Medical Sciences, Mashhad, Islamic Republic of Iran (Correspondence to A. Zabihi Zazoly: zabihia901@mums.ac.ir; arshad9067@yahoo.com).

Received: 01/02/14; accepted: 04/08/14 


\section{Introduction}

The cultural competence movement began almost 20 years ago (1). Although there is currently no standardized definition of cultural competence, Cross et al.'s definition is the most commonly cited (2). This defines cultural competence as "a set of congruent behaviours, attitudes, and policies that come together in a system, agency, or among professionals and enables that system, agency, or those professionals to work effectively in cross-cultural situations" (3). Three major areas of health research provide a context that addresses the importance of culturally competent care: health disparities; access to health care; and quality of care (4). In the context of health care, the components of cultural competence bridge the cultural gap that exists between providers and patients (5) and play a critical role in reducing health disparities and improving health outcomes for patients (6). When care is provided that takes patients' values and beliefs into account, it is likely to result, for example, in better access to health care and increased compliance with medication by patients (7). Conversely, a lack of cultural competence among health-care providers may lead to patient dissatisfaction (8).

The Islamic Republic of Iran has many ethnic and religious groups which have a variety of subcultures, languages, lifestyles, customs, traditions and different modes of livelihood (9-11). Nowadays, foreign migrants too constitute a large part of the country's population (12) and providing education for the increasing number of foreign students in the country has become an important issue in higher education (13). The cultural diversity of Iranian society raises challenges for the health-care system in trying to serve patients of diverse languages and cultures. Research in the Islamic Republic of Iran shows that beliefs about health care and people's perceptions of illness and health vary across ethnic and religious groups $(9,14)$.
Despite its long tradition in disciplines such as psychology, it is only within the past decades that cultural competence has been studied in the context of health and becomeintegrated into the medical education curriculum (15). In the educational realm, cultural competence has been defined as "the ability to successfully teach students who come from different cultures other than your own" (16). In their book, Diller and Moule stated that it entails developing certain personal and interpersonal awareness and sensitivities, developing certain bodies of cultural knowledge and mastering a set of skills that, taken together, underlie effective cross-cultural teaching (17). The available evidence on multicultural education addressing ethnic and religious diversity highlights the importance of providing cultural competence education and assessment of faculty staff members in the Islamic Republic of Iran. Faculty members act as role models and prepare their students to deliver culturally competent care (6). Yet cultural diversity poses a pedagogical and social challenge to educators (18); at all levels, they must develop cultural knowledge, awareness and sensitivity to help diverse learners (19).

Despite the clear importance of cultural competence in health care, there has been no research to develop a framework to specify the components of cultural competence in the Iranian context. The purpose of this study was to elucidate medical faculty members' perspectives on the components of cultural competence applicable to medical schools and how these compare with those found in the English language literature.

\section{Methods}

\section{Study design and participants}

Between October 2012 and September 2013, the authors conducted a qualitative study in Mashhad University of
Medical Sciences. Since there was no existing framework for cultural competence of faculty members in the Islamic Republic of Iran, we used an inductive and exploratory approach to understand the dimensions of cultural competence. We therefore chose a combination of methods, including archive study, semi-structured interviews and focus group discussions (FGD) to combine evidence and the collective perspective of experts. In the archive study, we reviewed the current evidence to identify the existing components of cultural competence and then we completed these components by semi-structured interviews and FGDs.

To obtain a range of perspectives on cultural competence, we recruited participants who were faculty members and educational experts at Mashhad University of Medical Sciences, who had had more than 15 years of experience in teaching, research and service and who were considered as role models in the university. The participants were selected through purposeful sampling (unique cases) and later on by snowball sampling. The inclusion criteria for the participants were having expertise in medical science, teaching and being active in medical education and ethics. Participants unwilling to participate were excluded. We invited 21 faculty members who had valuable educational experiences to participate in this study; 15 of them expressed their readiness to participate in FGDs and the remaining 6 faculty members were given individual interviews to accommodate their busy schedules,

\section{Data collection}

Table 1 summarizes the study steps and the participants at each stage.

\section{Step 1: archive study}

We reviewed the published literature and frameworks to identify the existing components of cultural competency. Between October 2012 and April 2013, we searched the databases 


\begin{tabular}{|c|c|c|c|c|}
\hline Sequence of steps & Aim of step & Participants & Activities conducted & Results \\
\hline Step 1: archive study & $\begin{array}{l}\text { To identify the existing } \\
\text { components of cultural } \\
\text { competence }\end{array}$ & Researchers & $\begin{array}{l}\text { Searching databases, } \\
\text { surveying articles and } \\
\text { documents, identifying } \\
\text { existing components } \\
\text { during } 40 \text { discussion } \\
\text { sessions }\end{array}$ & $\begin{array}{l}20 \text { components } \\
\text { in } 3 \text { domains were } \\
\text { identified relating to } \\
\text { cultural competence } \\
\text { of faculty members in } \\
\text { medical schools }\end{array}$ \\
\hline Step 2: interviews & $\begin{array}{l}\text { To identify the new } \\
\text { components of cultural } \\
\text { competence }\end{array}$ & $\begin{array}{l}\text { Researchers \& } 6 \\
\text { faculty members }\end{array}$ & $\begin{array}{l}\text { Conducting } 6 \text { interviews, } \\
\text { analysing data and } \\
\text { eliciting new components }\end{array}$ & $\begin{array}{l}\text { After deleting } \\
\text { duplicate } \\
\text { components, } 5 \text { new } \\
\text { components were } \\
\text { added }\end{array}$ \\
\hline Step 3: first FGD & $\begin{array}{l}\text { To identify the new } \\
\text { components of cultural } \\
\text { competence }\end{array}$ & $\begin{array}{l}\text { Researchers \& } 14 \\
\text { faculty members }\end{array}$ & $\begin{array}{l}\text { Conducting FGDs, } \\
\text { brain-storming and } \\
\text { summarizing findings }\end{array}$ & $\begin{array}{l}\text { After deleting } \\
\text { duplicate } \\
\text { components, } 3 \text { new } \\
\text { components were } \\
\text { added }\end{array}$ \\
\hline Step 4: questionnaire & $\begin{array}{l}\text { To determine the } \\
\text { importance of each } \\
\text { component (scoring round) }\end{array}$ & $\begin{array}{l}\text { Researchers \& } 21 \\
\text { faculty members }\end{array}$ & Scoring the components & $\begin{array}{l}\text { Mean score of all the } \\
\text { components was }>5\end{array}$ \\
\hline Step 5: second FGD & To finalize the components & $\begin{array}{l}\text { Researchers \& } 8 \\
\text { faculty members }\end{array}$ & $\begin{array}{l}\text { Preparing the final } \\
\text { framework }\end{array}$ & $\begin{array}{l}21 \text { components in } 3 \\
\text { domains were agreed } \\
\text { to define the cultural } \\
\text { competence of faculty } \\
\text { members in medical } \\
\text { schools }\end{array}$ \\
\hline
\end{tabular}

$F G D=$ focus group discussion .

of Google Scholar, ScienceDirect, PubMed, ProQuest, OvidMD, Education Resources Information Center (ERIC), WhereIsDoc, OhioLINK electronic theses and dissertation centre, the Iranian databases $\mathrm{Ma}$ giran and Scientific Information Database (SID), and the website of the Iranian Council of Cultural Revolution, with no specific time span to limit the search. The keywords used were: cultural competence, multicultural education, framework AND cultural competence, components of cultural competence, cultural competence AND faculty members, cultural competence AND medical science. We also consulted the databases of colleges and associations and publications from government and nongovernmental organizations including the Association of American Medical Colleges; the National Center for Cultural Competence (an initiative based at the Georgetown University Center for Child and Human Development); and the Liaison Committee on Medical Education (an accrediting body for educational programmes at schools of medicine in America and Canada). The publications and documents were mostly in English language. Articles were included if they were available as full texts; were written in English; reflected the components, elements or domains of cross-cultural competence; and were applicable to faculty members of a medical school. The identified articles were then screened and assessed for eligibility according to the inclusion criteria. The included articles were critically appraised with an assessment tool for descriptive and qualitative articles by 2 of researchers (M.M. and A.Z.). Another researcher (H.K.) moderated in the case of disagreement.

Based on their content and purpose, the aggregated results were classified into 3 categories related to the importance of cultural competence, education about cultural competence and assessment of cultural competence. This was done by the researchers in 12 discussion sessions lasting on average 2 hours.
Afterwards, 112 components were extracted by reviewing the obtained data, extracting key phrases and organizing concepts and meaning through 28 discussion session lasting on average 3 hours. Components that had similar meanings were combined and duplicate components were removed. Finally, 20 components in 3 domains - knowledge, attitude and practice - were identified as suitable for defining the cultural competence of faculty members in the medical school. The components were developed in Persian language and translated into English for reporting purposes.

\section{Step 2: interviews}

The semi-structured interviews were conducted with 6 faculty members. For consistency we used a single interviewer (A.Z.), although all the researchers participated in developing the interview guide. Interviews were tape-recorded if the respondent agreed. If the respondent did not agree the interviewer took notes and dictated the responses as close 
to verbatim as possible immediately following the interview. Each interview lasted approximately 30 minutes and was scheduled at a time and place that was convenient for the interviewee. We continued data collection until theoretical saturation was reached. We used the archive study to design the interview questions, which included items covering the domains and components of cultural competence.

\section{Step 3: first FGD}

We conducted 2 FGDs. We invited 15 medical school faculty members by e-mail and letter to participate in our sessions. FGDs were audio-recorded with the agreement of the participants. During each session, researchers took notes of the important points and gave the opportunity to all the members to express their comments and ideas.

The first FGD consisted of 7 faculty members from clinical science and 7 members from basic science. We provided copies of the questions and the needed information for the faculty members. Afterwards, one of the researchers (M.M.) presented relevant explanations and asked questions and then in a brain-storming session participants discussed the issues together.

\section{Step 4: questionnaire}

The main goal of Step 4 was validation of the components. The 28 components obtained from the previous steps were used to construct a questionnaire. Participants were asked to score the importance of each component from 0 (lowest score) to 10 (highest score). They were also requested to add additional components that they considered important and to provide comments about deleting or modifying the free text at the end of the questionnaire. This step was conducted face to face.

\section{Step 5: second FGD}

The second FGD included 4 faculty members from clinical science and 4 from basic science. After providing a report containing the results of Step
4 participants discussed the issues together. Some of the components were integrated or revised. Then general discussions took place for each component. When we believed we had reached saturation we finalized the components in this step.

\section{Data analysis}

Qualitative data were analysed using qualitative analysis and the inductive approach. The recorded interviews and FGDs were transcribed verbatim by 2 of researchers (M.M. and A.Z.). The same 2 researchers independently read each transcript, extracted important statements and phrases and formulated meanings for these statements. Statements and phrases from all participants that were similar were grouped together or clustered into one list of themes. The researchers (M.M. and A.Z.) sent the other researcher (H.K.) a copy of their results along with original descriptions for validation and confirmation of the consistency between these clusters and the original descriptions. Similar results were obtained. Then all the researchers (M.M., A.Z. and H.K.) combined the results and wrote an exhaustive description. We returned these finding to the participants to validate the findings. No new data were revealed from the participants.

Quantitative data were analysed using SPSS, version 11.5. We used descriptive statistics, including mean and standard deviation (SD) to analyse quantitative data from the scoring steps.

\section{Results}

Table 2 shows selected demographic characteristics of the participants, including age, sex, subject and academic rank. Most of the participants (81\%) were men and the largest proportion of participants were aged 46-50 years (38\%).

\section{Archive study}

Box 1 lists the 20 components in the 3 domains of knowledge, attitude and practice, based on the results of the archive study. Knowledge was defined as "Having awareness of the values, beliefs and norms of different ethnic, racial and cultural groups"; attitude was "Having the values, beliefs and understandings that are the foundation of professional

\begin{tabular}{|c|c|c|}
\hline Characteristic & No. & $\%$ \\
\hline \multicolumn{3}{|l|}{ Age (years) } \\
\hline$\leq 45$ & 4 & 19 \\
\hline $46-50$ & 8 & 38 \\
\hline $51-60$ & 5 & 24 \\
\hline$\geq 61$ & 4 & 19 \\
\hline \multicolumn{3}{|l|}{ Sex } \\
\hline Female & 4 & 19 \\
\hline Male & 17 & 81 \\
\hline \multicolumn{3}{|l|}{ Subject } \\
\hline Clinic science & 10 & 48 \\
\hline Basic science & 11 & 52 \\
\hline \multicolumn{3}{|l|}{ Academic rank } \\
\hline Professor & 6 & 29 \\
\hline Associate professor & 6 & 29 \\
\hline Assistant professor & 6 & 29 \\
\hline Lecturer & 3 & 14 \\
\hline
\end{tabular}




\section{Box 1 Initial list of components of cross-cultural competence of faculty members in medical school based on the archive study}

\section{Knowledge}

- Having awareness of relevant sources to obtain cultural information

- Having awareness of the risk of discrimination among people from different cultural backgrounds

- Having awareness of the different needs of people from different cultures

- Having awareness of non-verbal communication symbols in different cultures

- Having awareness of beliefs in various cultural communities

\section{Attitude}

- Accepting cultural diversity (customs, different ways of communication, beliefs, different traditions and perspectives)

- Having an altruistic viewpoint

- Understanding the risk of selecting one's own culture (her/his norms and professional values) as the correct culture (self centred)

- Believing in the need to be careful of one's behaviour regarding reactions to people from different cultural backgrounds

\section{Practice}

- Demonstrating a desire to respond to the client's cultural needs (e.g. patients, patient's family, students, colleagues and other clients)

- Having the ability to create a trustworthy relationship

- Expressing empathy

- Demonstrating a respectful attitude towards differences between people from different cultural backgrounds

- Being flexible in choosing the appropriate approach with clients from different cultures

- Allocating sufficient and appropriate time for clients

- Practising active listening

- Having good verbal communication skills

- Having the ability to use non-verbal communication skills and body language

- Having consideration for education about cultural competence for students in the area of professional activities

- Practising self-development in fields related to cultural competence (e.g. attending educational programmes, cultural trips, etc.)

norms"; and practice was "Demonstrating knowledge and attitude in behaviours and encounters".

\section{Interviews and FGDs}

The 8 new components, including 1 component in the domain of knowledge and 7 components in the domain of practice, were added to the previous components after analysing the interviews and the first $\mathrm{FGD}$ and eliminating the duplicate components. The following components were added. In the domain of knowledge we added: "Having awareness of one's limitations regarding cultural context and issues". In the domain of practice the following were added: "Maintaining equity in professional behaviour in encounters with people from different cultures"; "Having appropriate behaviour in cultural encounters", "Having appropriate appearance (e.g. clothing) considering the beliefs of the local culture"; "Being open to criticism and tactful about giving criticism to others"; "Having modesty in expression"; "Cultural production (e.g. faculty members should make their own experiences and ideas viable and lasting)"; and "Having tolerance in encounters with different cultures in the area of professional activities".

In the validation step the mean scores ranged from 6.9 to 9.3 and the mean of all the components was greater than 5 (out of 10), indicating that all of them were considered important. The highest score [mean 9.3 (SD 0.57)] was given to the component "Accepting cultural diversity (customs, different ways of communication, beliefs, different traditions and perspectives)" from the attitude domain. The lowest score [mean 6.9 (SD 0.9)] was given to "Having awareness of non-verbal communication symbols in different cultures" from the knowledge domain.
No new components were added by the participants.

In the second FGD, we changed the name of the "practice" domain to "behaviour". Six components were combined-"Having the ability to use non-verbal communication skills and body language", "Having good verbal communication skills", "Practising active listening", "Expressing empathy", "Having modesty in expression" and "Having appropriate behaviour in culturalencounters" - and the component "Having good verbal and non-verbal communication skills" was created. Two components were eliminated"Allocating sufficient and appropriate time for clients"; "Having tolerance in encounters with different cultures in the area of professional activities" - since other components already covered their concept. The components of "Having appropriate appearance (e.g. clothing etc.) considering the beliefs of the local 


\section{Knowledge}

\section{Box 2 Final list of components of cross-cultural competence of faculty members in medical schools}

- Having awareness of information resources about different ethnic and religious cultures

- Having awareness of the risk of discrimination towards people from different cultural backgrounds

- Having awareness of the diversity of needs of people from different cultures

- Having awareness of non-verbal communication symbols in different cultures

- Having awareness of beliefs in various cultural communities

- Having awareness of one's own limitations (knowledge, communication, practical) concerning different ethnic and religious cultures

\section{Attitude}

- Accepting cultural diversity (e.g. customs, different ways of communication, beliefs, different traditions and perspectives)

- Having an altruistic point of view

- Understanding the risk of selecting one's own culture (own norms and values in profession) as the correct culture in professional behaviour (culturally self-centred)

- Believing in the need to care about professional behaviour in interactions with people from different cultures

\section{Behaviour}

- Demonstrating the desire to respond to the needs of clients from different cultures (e.g. patients, patient's family, students, colleagues and other clients)

- Having the ability to build trustworthy relationships with clients from different cultures

- Demonstrating a respectful manner towards cultural differences among people in the area of professional activities (e.g. being respectful to different experiences and perspectives)

- Being flexible in choosing the appropriate approach with clients from different cultures

- Having good verbal and non-verbal communication skills

- Considering education in cultural competence for students in the area of professional activities

- Practising self-development in fields of cultural competence (e.g. attending educational programmes, cultural trips, etc.)

- Maintaining equity and fairness in professional behaviour in encounters with people from different cultures

- Having appearance appropriate to accepted norms of society

- Being open to criticism and tactful about giving criticism to others

- Making one's own experiences and ideas viable and lasting (cultural production)

culture" and "Cultural production (faculty members should make their own experiences and ideas viable and lasting)" were transformed into "Having appearance appropriate to accepted norms of society" and "Making one's own experiences and ideas viable and lasting (cultural production)". Other components were modified in terms of their word structure and the final list of components were prepared and accepted by all the participants (Box 2).

\section{Discussion}

A major portion of the cultural competence literature can be found in the fields of health care and social work (20). Most of the frameworks we identified originated from North America $(21-23)$, although some had been developed in the United Kingdom (24) and New Zealand (25). Despite some differences, the existing frameworks for cultural competence have much in common (25). The components of cultural competence, however, need to be determined for each country, based on its specific goals, vision and population characteristics. These components are also likely to reflect a country's political, historical and sociocultural features. There are now many examples of frameworks, standards and models for cultural competence-e.g. the Accreditation Readiness Standards for Culturally Competent Healthcare Practitioners under the Joint Commission's 21 standards and the Culturally and Linguistically Appropriate Services (CLAS) standards - but they have not been exclusively developed to relate to medical faculty members (26-28). Existing frameworks are used to assess the competence both of students and faculty members as well as other healthcare personnel, and these place less emphasis on the interaction between faculty members and students of culturally diverse backgrounds and more emphasis on the faculty members being role models and training providers of cultural competence for students. In our study in the Islamic Republic of Iran, both of these situations were considered. Participants in the current study identified ethnic and religious diversity as important factors and emphasized the development of knowledge, attitude and behaviour based on this. Participants did not identify racism and discrimination as significant issues.

In current study, the 21 components of cultural competence identified were categorized into 3 major domains: knowledge (6 components), attitude (4 components) and behaviour (11 
components). Many standards and guidelines that are currently used to define cultural competence-e.g. the standards of the Medical Council of New Zealand and frameworks of cultural competence from North Ameri$\mathrm{Ca}$-are based on these same domains $(25,29)$.

Our participants expressed the importance of knowledge as a precursor to changing an attitude; therefore, knowledge was placed before attitude in this study and included 6 components related to knowledge and awareness of values, beliefs and norms of different ethnic, racial and cultural groups. In some of the existing frameworks, e.g. that of Jirwe et al. (25), cultural sensitivity is seen as a precursor to culturally appropriate care. The 4 components of attitude in our study are similar to their study regarding cultural sensitivity. In our study, behaviour included 11 components related to demonstrating knowledge and to attitude in behaviour and encounters. More specifically, key aspects of cross-cultural competence include the ability to manage language barriers, communication styles, mistrust and prejudice, family dynamics, customs and spirituality, and sexual and gender issues. Cross-cultural competence depends also on demonstrating empathy, curiosity and respect, which are key factors for effective patient care in a multicultural context (30). In the current study, the identified components of behaviour also included these aspects.
Many studies and frameworks, e.g. the Tool for Assessing Cultural Competence Training (TACCT), and the models of Campinha-Bacote and Jirwe et al., have emphasized the importance of establishing effective communication skills in cross-cultural encounters $(23,25,31)$. In the current study, the following components emphasized this issue: "Having the ability to build trustworthy relationships with clients from different cultures" and "Having good verbal and non-verbal communication skills". Many existing frameworks and components, e.g. TACCT, have emphasized health disparities. In our study, the component of "Maintaining equity and fairness in professional behaviour in encounters with people from different cultures" focuses on disparities. Some of the components in the current study highlight the interaction between faculty members and students, e.g. "Making one's own experiences and ideas viable and lasting (cultural production)", "Having consideration for education about cultural competence for students in the area of professional activities" and "Being open to criticism and tactful about giving criticism to others". Furthermore, these 3 components are also relevant to interactions with other clients.

There are some limitations to this study that could be addressed and used to guide future research in this area. Although we invited faculty members who had had educational experience at universities of different areas in Islamic
Republic of Iran, the number of experts was limited. Secondly, the study was only conducted at one institution. Further research is needed to among a wider group of faculty members.

\section{Conclusions}

Available evidence from multicultural education addressing ethnic and religious diversity highlights the importance of education and assessment of cultural competence in faculty members and students of medical science. A comprehensive educational strategy must be developed for assessment among faculty members and students in the Islamic Republic of Iran. The components developed in this study will provide guidance to develop a tool to assess the cross-cultural competence of faculty members in Iranian medical schools.

\section{Acknowledgements}

We would like to thank the Vice Chancellor for Research of Mashhad University of Medical Science. We would also like to thank the faculty members who participated in this study for providing their time and thoughtful comments.

Funding: This research was financially supported by the Vice Chancellor for Research of Mashhad University of Medical Science (code: 920613).

Competing interests: None declared.

\section{References}

1. Vega WA. Higher stakes ahead for cultural competence. Gen Hosp Psychiatry. 2005 Nov-Dec;27(6):446-50. PMID:16271660

2. Chun MB, Young KG, Jackson DS. Incorporating cultural competency into the general surgery residency curriculum: a preliminary assessment. Int J Surg. 2009 Aug;7(4):368-72. PMID:19527802

3. Cross TL, Bazron BJ, Dennis KW, Isaacs MR. Towards a culturally competent system of care. Washington (DC): CASSP Technical Assistance Center, Georgetown University Child Development Center; 1989.

4. American Institutes for Research. Teaching cultural competence in health care: a review of current concepts, policies and practices. Washington (DC): Office of Minority Health, US Department of Health and Human Services; 2002 (http:// minorityhealth.hhs.gov/assets/pdf/checked/1/em01garcial. pdf, accessed 16 September 2014).

5. Betancourt JR. Cultural competence and medical education: many names, many perspectives, one goal. Acad Med. 2006 Jun;81(6):499-501. PMID:16728795

6. Burke PM. Cultural competency of associate degree nursing faculty [dissertation]. Minneapolis (MN): School of Education, Capella University; 2011.

7. Engebretson J, Mahoney J, Carlson ED. Cultural competence in the era of evidence-based practice. J Prof Nurs. 2008 MayJun;24(3):172-8. PMID:18504032 
8. Ihara E. Cultural competence in health care: is it important for people with chronic conditions? Washington (DC): Georgetown Health Policy Institute; 2004 (Issue Brief No. 5) (http:// hpi.georgetown.edu/agingsociety/pubhtml/cultural/cultural. html, accessed 16 September 2014).

9. Abbasi Shavazi M, Sadeghi R. Ethnicity and fertility: analysis of fertility behaviors of ethnic groups in Iran. Nameh-ye Olum-e Ejtemai. 2006;(29):29-58.

10. Nasaj H. Globalization and identity of Iranian ethnics. Iranian Pizhuhishi-i ulum-i Syasi. 2009;(5):129-56.

11. Gholizadeh A, Kashtiaray N, Sohrabi Renani M. Management skills of cultural diversity as a response to demands of students of ethnic and religious minorities. Quarterly Journal of New Approaches in Educational Administration. 2011;2(2):131-54.

12. Sadeghi R. Population characteristics of foreign immigrants in Iran. Iranian Journal of Official Statistics Studies. 2009;20(1):4173.

13. Fathi Vajargah K, Arefi M, Zamanimanesh H. [Evaluating admission barriers of foreign students into universities and institutions of higher education]. Quarterly Journal of Research and Planning in Higher Education. 2011;62 [in Farsi].

14. Kalantari S, Ghana S. MahstiJoybari L, Sharifniya H, Sanago A. [The attitudes of Golestan University of Medical Sciences toward abortion]. Med Ethics (Burlingt, Mass). 2012;6(19):134-48 [in Farsi].

15. Wilkinson JE. Use of a writing elective to teach cultural competency and professionalism. Fam Med. 2006 NovDec;38(10):702-4. PMID:17075742

16. Nieto C, Zoller Booth M. Cultural competence: its influence on the teaching and learning of international students. Journal of Studies in International Education. 2010;14(4):406-25.

17. Promoting educators' cultural competence to better serve culturally diverse students. Washington (DC): Center for Great Public Schools; 2008 (an NEA policy brief) (http://www. massmabe.org/upload/PB13_CulturalCompetence08.pdf, accessed 15 December 2014).

18. Qureshi A, Collazos F, Ramos M, Casas M. Cultural competency training in psychiatry. Eur Psychiatry. 2008 Jan;23 Suppl 1:49-58. PMID:18371580

19. Kumaş-Tan Z, Beagan B, Loppie C, MacLeod A, Frank B. Measures of cultural competence: examining hidden assumptions. Acad Med. 2007 Jun;82(6):548-57. PMID:17525538

20. Booker NM. Cultural competence: educating public school teacher candidates in matters of diversity [PhD thesis]. Akron
$(\mathrm{OH})$ : Department of Public Administration, University of Akron; 2009.

21. Lipson JG, Steiger NJ. Self-care nursing in a multicultural context. Thousand Oaks (CA): Sage Publications, 1996.

22. Purnell L. The Purnell model for cultural competence. J Transcult Nurs. 2002 Jul;13(3):193-6. PMID:12113149

23. Campinha-Bacote J. The process of cultural competence in the delivery of healthcare services: a model of care. J Transcult Nurs. 2002 Jul;13(3):181-4. PMID:12113146

24. Papadopoulos I, Tilki M, Taylor G. Transcultural care: a guide for health care professionals. Slough, United Kingdom: Quay Books; 1998.

25. Jirwe M, Gerrish K, Keeney S, Emami A. Identifying the core components of cultural competence: findings from a Delphi study. J Clin Nurs. 2009 Sep;18 (18):2622-34. PMID:19538568

26. Hines D. Cultural competence: assessment and education resources for home care and hospice clinicians. Home Healthc Nurse. 2012 Jan;30(1):38-45. PMID:22173617

27. Naughton J, Adayana Healthcare Group. Cultural competency in healthcare. Indianapolis (IN): Adayana Government Group; 2009 (http://www.adayana.com/sites/default/files/docs/ Cultural\%20Competency\%20in\%20Healthcare\%20Whitepaper_1.pdf, accessed 16 September 2014).

28. Grote E. Principles and practices of cultural competency: a review of the literature. Canberra, Australian Capital Territory: Indigenous Higher Education Advisory Council; 2008 (http://www.deewr.gov.au/Indigenous/HigherEducation/ Programs/IHEAC/Documents/PrinciplePracCulturalComp. pdf, accessed 16 September 2014).

29. Statement on cultural competence. August 06. Auckland: Medical Council of New Zealand; 2006 (http://www.mcnz. org.nz/assets/News-and-Publications/Statements/Statement-on-cultural-competence.pdf, accessed 16 September 2014)..

30. Bardet A, Green AR, Paroz S, Singy P, Vaucher P, Bodenmann P. Medical residents' feedback on needs and acquired skills following a short course on cross-cultural competence. Int J Med Educ. 2012;3:107-14.

31. Lie D. A framework for enhancing and assessing cultural competency training. Kaohsiung J Med Sci. 2009 Sep;25(9):48692. PMID:19717367 